Sādhanā Vol. 37, Part 4, August 2012, pp. 503-520. (C) Indian Academy of Sciences

\title{
Optimization of burnishing parameters and determination of select surface characteristics in engineering materials
}

\author{
P RAVINDRA BABU ${ }^{1}$, K ANKAMMA ${ }^{2}$, T SIVA PRASAD ${ }^{3}$, \\ $\mathrm{A} \mathrm{V} \mathrm{S} \mathrm{RAJU}^{4}$ and N ESWARA PRASAD ${ }^{5, *}$ \\ ${ }^{1}$ Mechanical Engineering Department, Gudlavalleru Engineering College, \\ Gudlavalleru 521 356, India \\ ${ }^{2}$ Mechanical Engineering Department, Mahatma Gandhi Institute of Technology, \\ Hyderabad 500 075, India \\ ${ }^{3}$ Mechanical Engineering Department, C Mallareddy college of Engineering, \\ Secunderabad 500 114, India \\ ${ }^{4}$ Mechanical Engineering Department, Jawaharlal Nehru Technological University, \\ Hyderabad 500 072, India \\ ${ }^{5}$ Regional Centre for Military Airworthiness (Materials), CEMILAC, \\ PO Kanchanbagh, Hyderabad 500 058, India \\ e-mail: nep@cemilac.drdo.in
}

MS received 25 June 2011; revised 23 January 2012; accepted 3 February 2012

\begin{abstract}
The present study is aimed at filling the gaps in scientific understanding of the burnishing process, and also to aid and arrive at technological solutions for the surface modifications based on burnishing of some of the commonly employed engineering materials. The effects of various burnishing parameters on the surface characteristics, surface microstructure, micro hardness are evaluated, reported and discussed in the case of EN Series steels (EN 8, EN 24 and EN 31), Aluminum alloy (AA6061) and Alpha-beta brass. The burnishing parameters considered for studies principally are burnishing speed, burnishing force, burnishing feed and number of passes. Taguchi technique is employed in the present investigation to identify the most influencing parameters on surface roughness. Effort is also made to identify the optimal burnishing parameters and the factors for scientific basis of such optimization. Finally, a brief attempt is made to construct the Burnishing maps with respect to strength level (in this case, average micro hardness of unburnished material).
\end{abstract}

Keywords. Roller burnishing; surface roughness; microstructure; micro hardness; residual stresses; burnishing maps.

*For correspondence 


\section{Introduction}

Surface modifications and surface treatments play vital role in enhancing service life of many critical parts of materials and devices that are used for engineering and/or structural applications. Modern technologies employ advanced surface modification techniques, such as laser treatment and coatings to enhance service life. However, most of these advanced technologies are prohibitively expensive and economically unviable for simple to moderate critical applications such as those for automobiles and machine parts. In these circumstances, traditional surface modifications that result in surface roughness values of the order of 0.1 to $0.2 \mu \mathrm{m}$ are desirable. Numerous past studies have indicated that post-machining and metal-finishing operations have become attractive (Belov 1966; Papshev 1966; Torbilo \& Markus 1969; Shapiro \& Frolov 1970; Timoshchenko \& Dubenko 1976; Ruseva \& Fuks 1978; Kotiveerachari \& Murthy 1989; Rajesham \& Jem Cheong Tak 1989). One such process is 'Burnishing' which improves surface characteristics by plastically deforming the surface layers. Though burnishing has been widely employed, no systematic studies have been conducted or reported till date, which elucidate the effects of all burnishing processing parameters on the surface finish, surface residual stress, micro structure and micro hardness. Burnishing is considered as cold-working finishing process which produces good surface finish and residual compressive stresses at metallic surface layers. It distinguishes itself from chip-forming finishing processes such as grinding, honing, lapping and super finishing, which induce residual tensile stresses at the surface, while burnishing results in residual compressive stresses. Moreover, burnishing is economical and requires less time and skill to obtain a high quality surface finish. The study of surface finish that results from burnishing is very much essential because the fatigue life, bearing properties and lubrication of a part depends largely on the appropriate surface finish (Chepa \& Andrayshin 1973), which ultimately decides the effectiveness of burnishing process. If the surface finish is high, then seizure would occur due to difficulty of maintaining the lubricating oil film. On the other hand, if the surface finish is low, the hills in irregular surface reduce the metal to metal contact and valleys help to retain the film of lubricating oil; but, cannot as low surface finish leads to high wear and fatigue resistance. In order to increase the life of any part which is subjected to repeated reversals of stress, the working and non-working surfaces of that part must be given good surface finish as economically as possible. Constant surface roughness, a desirable feature can be achieved over a wide range of process conditions through hard roller burnishing (Vyallo 1965; Sheider 1967, 1970; Jack \& Marion 1992; Brinksmeier 1982; Kotiveerachari \& Murthy 1988; Phadke 1989; Phillip Ross 2008).

The present research aims at arriving optimum burnishing parameters for a variety of materials with characteristic strength level (in the present case varied average micro hardness) the materials considered are EN series steels, AA6061 alloy, alpha-beta brass and the burnishing parameters evaluated include burnishing force, burnishing feed, burnishing speed and number of passes. Systematic experiments have been conducted based on a 2 and 3 level Taguchi's design experiment method. Unlike many investigations reported in the open literature, the present paper also addresses the variation of micro hardness with radial distance and depth of burnishing obtained using optical microscope. The optimal burnishing parameters have been evaluated and reported in section 4.1 (results and discussion). Based on these data, an attempt has been made for the first time to report the 'burnishing maps' considering average micro hardness of the un-burnished materials and optimized values of burnishing volumes that has resulted in highest surface finish and highest compressive residual stresses. 


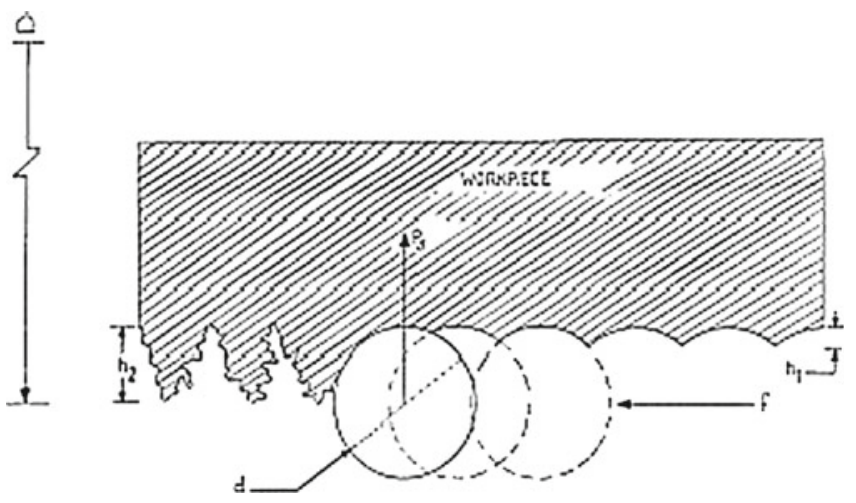

Figure 1. Burnishing process.

\section{Burnishing}

Burnishing is considered as a cold-working finishing process, differing from other cold-working, surface treatment processes such as shot peening and sand blasting, etc. In that it produces a good surface finish and also induces residual compressive stresses at the metallic surface layers. The changes in surface characteristics due to burnishing will cause improvements in surface hardness, wear resistance, fatigue resistance, yield and tensile strength and corrosion resistance. It can be seen from the figure 1 that the ball or roller rotates by the effect of frictional engagement between the surface of the ball or roller and the surface of the work piece.

\section{Experimental}

In order to establish the clear picture of burnishing process, a series of experiments were conducted on metals which find wide range of industrial applications, namely EN 8, EN 24, EN 31 alloy steels, AA6061 alloy and alpha-beta brass to study the fundamental aspects of the process. The chemical composition of the alloys is as follows.

EN 8:C:0.35-0.45, Si:0.05-0.30, Mn:0.60-1.0, S: $0.06(\max )$ and P: $0.06(\max )$

EN 24:C:0.35-0.45, Si:0.10-0.35, Mn:0.45-0.70, Cr: 0.22-0.35, Ni:1.03-1.08

EN 31:C:0.90-1.20, Si:0.10-0.35, Mn:0.30-0.75, Cr: 1.0-1.6, Ni:1.03-1.08

AA6061:Al: 95.85-98.56, Cr:0.04-0.35, Fe:0-0.7, Mg:0.8-1.2, Mn:0.15 (max), Si:0.4-

0.8, Ti:0.15 $(\max ), \mathrm{Zn}: 0.25(\max )$ and $\mathrm{Cu}: 0.15-0.4$

$\alpha-\beta$ Brass:Cu:58.46, Zn:37.78, Pb:1.9, Sn:0.83, Fe: 0.24, Al:0.11, Ni:0.1 and Si:0.07.

Burnishing experiments were conducted on external surfaces with roller burnishing tools. In the experiments, the work pieces were burnished after turning on lathe, in the same set-up. While burnishing, the roller burnishing tool was fixed in lathe tool dynamometer. The dynamometer is capable of measuring three force components. The z- component was taken as the burnishing force. The burnishing experiments have been devised based on Taguchi techniques. The most influencing parameters in affecting surface roughness is obtained using column effect method. For the same a full factorial orthogonal array is chosen. The full factorial experiment for three 
Table 1. The factors and levels chosen for experimentation (common for all the three EN steels).

\begin{tabular}{lccc}
\hline Factors & Level 1 & Level 2 & Level 3 \\
\hline Speed, RPM & 225 & 355 & 535 \\
Force, N & 170 & 200 & 210 \\
Feed, $\mathrm{mm} / \mathrm{rev}$ & 0.063 & 0.095 & 0.111 \\
\hline
\end{tabular}

factors at 3-level requires $27\left(3^{3}\right)$ experiments (table 1), a L-27 orthogonal array (table 2) is selected. For three factors and the columns to be selected are 1,2 and 5. The factors selected and the levels chosen for the experimentation are shown in table 3 . The results are analysed using column effect method at levels 1, 2 and 3 are summed up and the difference at maximum and minimum values are obtained. Higher the difference for a parameter, higher is the influence

Table 2. L - 27 Orthogonal array selected for EN 8 steel (similar arrays with different corresponding data for all other materials: EN 24, EN 31, AA6061 and alpha-beta brass).

\begin{tabular}{lcccc}
\hline S. No & Level 1 & Level 2 & Level 3 & Roughness, $\mu \mathrm{m}(\mathrm{Ra})$ \\
\hline 1 & 225 & 170 & 0.063 & 0.67 \\
2 & 225 & 170 & 0.095 & 0.92 \\
3 & 225 & 170 & 0.111 & 1.09 \\
4 & 225 & 200 & 0.063 & 0.10 \\
5 & 225 & 200 & 0.095 & 0.11 \\
6 & 225 & 200 & 0.111 & 0.17 \\
7 & 225 & 210 & 0.063 & 0.67 \\
8 & 225 & 210 & 0.095 & 0.92 \\
9 & 225 & 210 & 0.111 & 1.09 \\
10 & 355 & 170 & 0.063 & 1.91 \\
11 & 355 & 170 & 0.095 & 1.08 \\
12 & 355 & 170 & 0.111 & 0.77 \\
13 & 355 & 200 & 0.063 & 0.43 \\
14 & 355 & 200 & 0.095 & 0.38 \\
15 & 355 & 200 & 0.111 & 0.23 \\
16 & 355 & 210 & 0.063 & 1.91 \\
17 & 355 & 210 & 0.095 & 1.08 \\
18 & 355 & 210 & 0.111 & 0.77 \\
19 & 535 & 170 & 0.063 & 0.75 \\
20 & 535 & 170 & 0.095 & 0.33 \\
21 & 535 & 170 & 0.111 & 0.57 \\
22 & 535 & 200 & 0.063 & 0.33 \\
23 & 535 & 200 & 0.095 & 0.34 \\
24 & 535 & 200 & 0.111 & 0.19 \\
25 & 535 & 210 & 0.063 & 0.75 \\
26 & 535 & 210 & 0.095 & 0.33 \\
27 & 535 & 210 & 0.111 & 0.57 \\
\hline & & & &
\end{tabular}




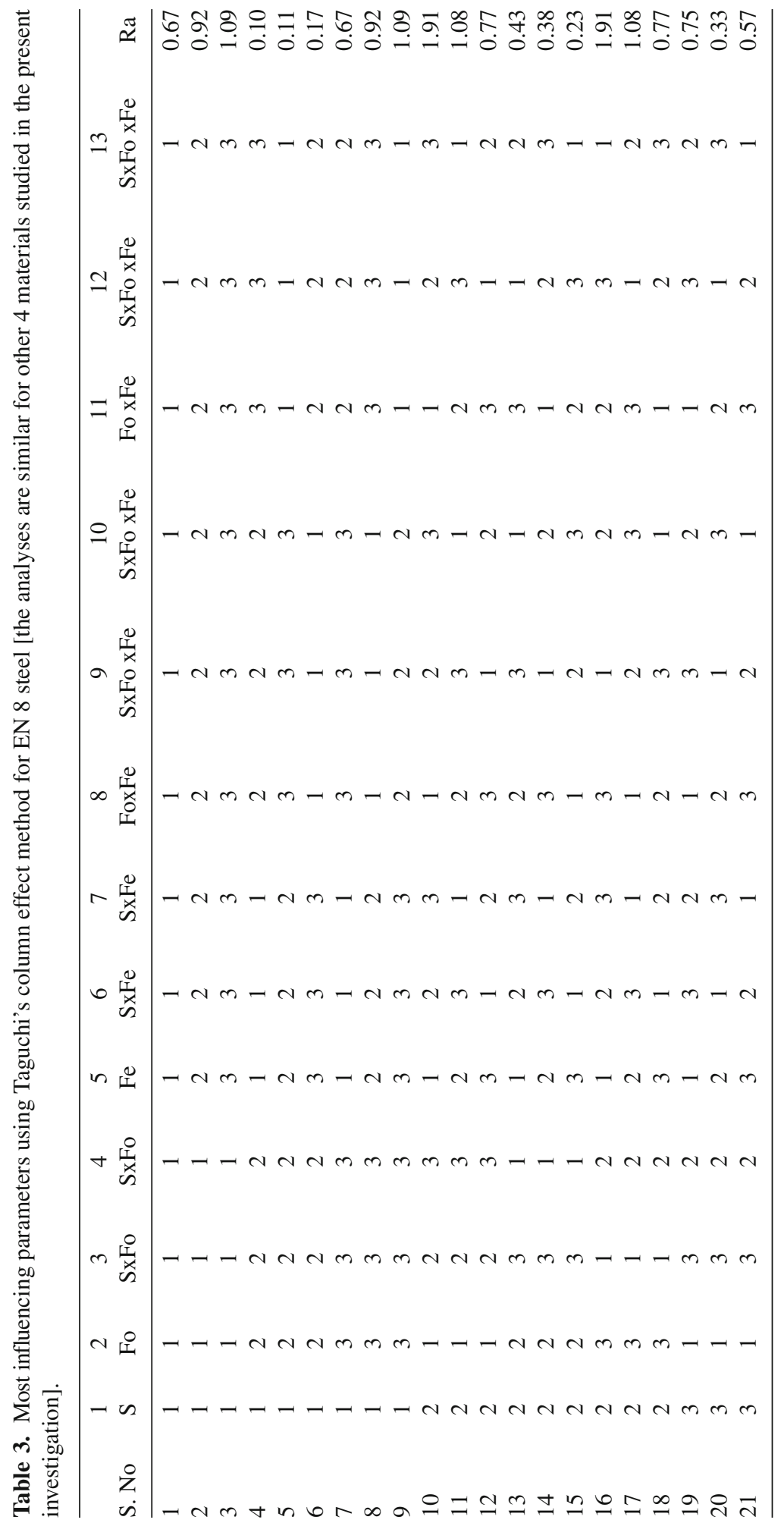




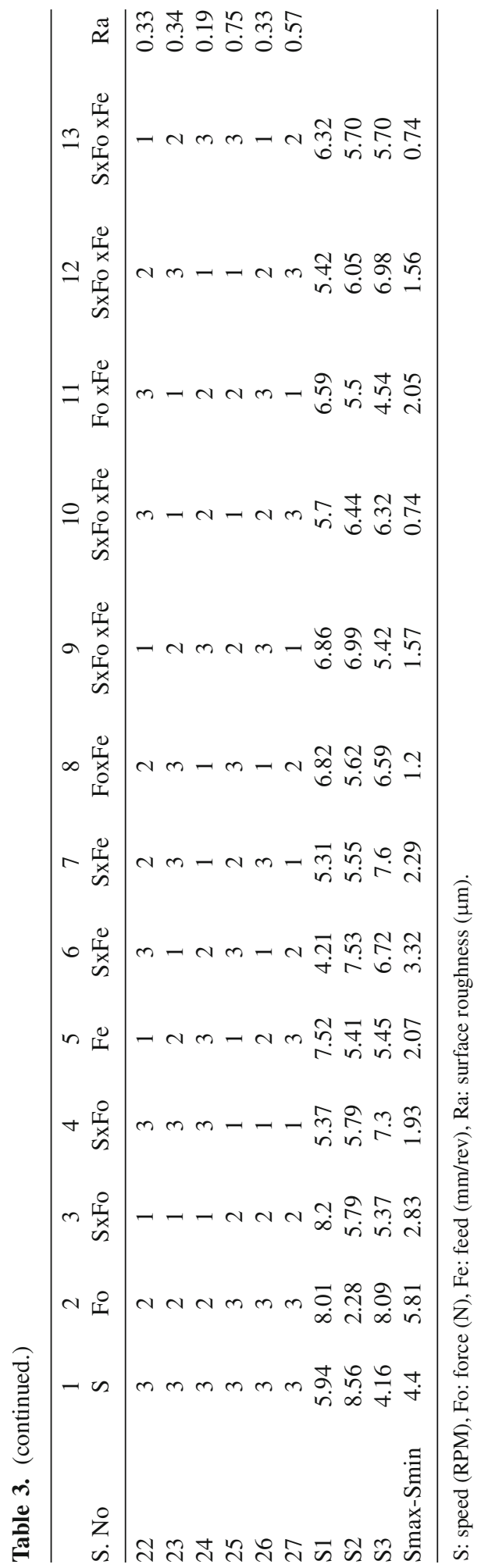


parameter in the output values. From the data in table 3, it is seen that the value of $S_{\max }-S_{\min }$ is 4.4 for speed, 5.81 for force and 1.93 for feed. So it can be stated that force is the most influencing parameter.

Stylus attached to the detector unit will trace minute irregularities of surface of work piece, processed and displayed on LCD, thus determining surface roughness up to $350 \mu \mathrm{m}$. The micro hardness values are obtained as a function of radial distance from burnished surface to the center. A micro hardness machine (Model: Micromet 2100, Buchler Ltd, USA) with Vickers indenter and $500 \mathrm{~g}$ indenter load was employed for this purpose.

Select and limited number of studies have been conducted using optical microscopes to record the micro structural features (especially the grain structure, inclusion, distribution and surface micro structure) of all the three category of experimental alloys before and after burnishing. For this, an optical microscope (Model: Leica DMLM upright) has been used.

\section{Results and discussion}

\subsection{Surface roughness}

The values of surface finish, a direct measurement of surface roughness before and after burnishing as a function of burnishing speed and burnishing feed are given in tables 4 and 5, respectively. The optimal forces considered for EN 8, EN 24 and EN 31 are $210 \mathrm{~N}, 170 \mathrm{~N}$ and $200 \mathrm{~N}$, respectively. The feed for all materials is taken as $0.032 \mathrm{~mm} / \mathrm{rev}$. From these data (data in tables 4 and 5 and figures 2 and 3) optimal speed, force and feed values which result in highest increase in surface finish are determined and the same are given in table 6.

Table 4. Comparison of surface finish values before and after burnishing for a $30 \mathrm{~mm}$ diameter work piece of alloy steels as a function of burnishing speed.

\begin{tabular}{|c|c|c|c|c|c|c|c|c|}
\hline \multirow[b]{2}{*}{ Material } & \multirow[b]{2}{*}{$\begin{array}{c}\text { Burnishing } \\
\text { speed }(\mathrm{m} / \mathrm{min})\end{array}$} & \multirow{2}{*}{$\begin{array}{c}\text { Surface finish } \\
\text { before burnishing } \\
\mathrm{R}_{\mathrm{a}}(\mu \mathrm{m})\end{array}$} & \multicolumn{3}{|c|}{$\begin{array}{l}\text { Surface finish after } \\
\text { burnishing } R_{a}(\mu \mathrm{m})\end{array}$} & \multicolumn{3}{|c|}{$\begin{array}{l}\% \text { increase in } \\
\text { surface finish }\end{array}$} \\
\hline & & & $\begin{array}{l}\text { First } \\
\text { pass }\end{array}$ & $\begin{array}{l}\text { Second } \\
\text { pass }\end{array}$ & $\begin{array}{l}\text { Third } \\
\text { pass }\end{array}$ & $\begin{array}{l}\text { First } \\
\text { pass }\end{array}$ & $\begin{array}{l}\text { Second } \\
\text { pass }\end{array}$ & $\begin{array}{l}\text { Third } \\
\text { pass }\end{array}$ \\
\hline \multirow[t]{5}{*}{ EN 8} & 51 & 1.32 & 0.10 & 0.11 & 0.17 & 92.42 & 91.66 & 87.121 \\
\hline & 34 & 1.62 & 0.43 & 0.38 & 0.23 & 91.98 & 76.54 & 85.80 \\
\hline & 22 & 1.39 & 0.33 & 0.34 & 0.19 & 76.26 & 75.54 & 86.34 \\
\hline & 14 & 1.31 & 1.04 & 0.92 & 0.35 & 20.61 & 29.77 & 73.28 \\
\hline & 9 & 1.32 & 0.24 & 0.19 & 0.22 & 81.81 & 85.60 & 83.33 \\
\hline \multirow[t]{5}{*}{ EN 24} & 51 & 2.00 & 0.25 & 0.27 & 0.56 & 87.50 & 86.50 & 72.00 \\
\hline & 34 & 3.88 & 0.36 & 0.15 & 0.26 & 90.72 & 96.13 & 93.30 \\
\hline & 22 & 3.92 & 0.18 & 0.17 & 0.27 & 95.41 & 95.66 & 93.11 \\
\hline & 14 & 3.48 & 0.48 & 0.62 & 0.90 & 86.20 & 82.18 & 74.14 \\
\hline & 9 & 3.71 & 0.53 & 0.51 & 0.92 & 85.72 & 86.25 & 75.20 \\
\hline \multirow[t]{5}{*}{ EN 31} & 51 & 0.99 & 0.62 & 0.38 & 0.92 & 37.37 & 61.61 & 07.07 \\
\hline & 34 & 0.81 & 0.11 & 0.13 & 0.18 & 86.45 & 84.00 & 77.77 \\
\hline & 22 & 0.98 & 0.28 & 0.20 & 0.12 & 71.43 & 79.60 & 87.75 \\
\hline & 14 & 1.18 & 0.23 & 0.19 & 0.21 & 80.51 & 83.90 & 82.20 \\
\hline & 9 & 0.77 & 0.20 & 0.22 & 0.70 & 74.02 & 71.43 & 09.09 \\
\hline
\end{tabular}


Table 5. Comparison of surface finish values before and after burnishing for a $30 \mathrm{~mm}$ diameter work piece of alloy steels as a function of burnishing feed.

\begin{tabular}{|c|c|c|c|c|c|c|c|c|}
\hline \multirow[b]{2}{*}{ Material } & \multirow{2}{*}{$\begin{array}{l}\text { Burnishing } \\
\text { feed } \\
\mathrm{mm} / \mathrm{rev}\end{array}$} & \multirow{2}{*}{$\begin{array}{c}\text { Surface finish } \\
\text { before burnishing } \\
\mathrm{R}_{\mathrm{a}}(\mu \mathrm{m})\end{array}$} & \multicolumn{3}{|c|}{$\begin{array}{l}\text { Surface finish after } \\
\text { burnishing } R_{a}(\mu \mathrm{m})\end{array}$} & \multicolumn{3}{|c|}{$\begin{array}{l}\% \text { increase in } \\
\text { surface finish }\end{array}$} \\
\hline & & & $22 \mathrm{~m} / \mathrm{min}$ & $34 \mathrm{~m} / \mathrm{min}$ & $51 \mathrm{~m} / \mathrm{min}$ & $22 \mathrm{~m} / \mathrm{min}$ & $34 \mathrm{~m} / \mathrm{min}$ & $51 \mathrm{~m} / \mathrm{min}$ \\
\hline \multirow[t]{4}{*}{ EN 8} & 0.111 & 1.32 & 0.75 & 1.11 & 0.67 & 43.18 & 15.90 & 49.24 \\
\hline & 0.095 & 1.62 & 0.33 & 1.08 & 0.92 & 79.63 & 33.33 & 43.21 \\
\hline & 0.063 & 1.31 & 0.57 & 0.77 & 1.09 & 56.48 & 41.22 & 16.80 \\
\hline & 0.032 & 1.32 & 0.19 & 0.43 & 0.10 & 85.60 & 67.42 & 92.42 \\
\hline \multirow[t]{4}{*}{ EN 24} & 0.111 & 2.00 & 0.25 & 0.37 & 1.70 & 87.5 & 81.50 & 15.00 \\
\hline & 0.095 & 3.88 & 0.54 & 0.22 & 0.97 & 86.08 & 94.32 & 75.00 \\
\hline & 0.063 & 3.92 & 0.42 & 0.32 & 2.18 & 89.28 & 90.45 & 44.39 \\
\hline & 0.032 & 1.8 & 0.18 & 0.36 & 0.25 & 90.00 & 80.00 & 86.11 \\
\hline \multirow[t]{4}{*}{ EN 31} & 0.111 & 0.99 & 0.33 & 0.19 & 0.75 & 66.66 & 80.80 & 24.24 \\
\hline & 0.095 & 0.81 & 0.34 & 0.13 & 0.44 & 58.02 & 83.95 & 45.68 \\
\hline & 0.063 & 0.98 & 0.72 & 0.20 & 0.51 & 26.53 & 79.59 & 47.95 \\
\hline & 0.032 & 1.18 & 0.28 & 0.11 & 0.62 & 76.27 & 90.67 & 47.45 \\
\hline
\end{tabular}
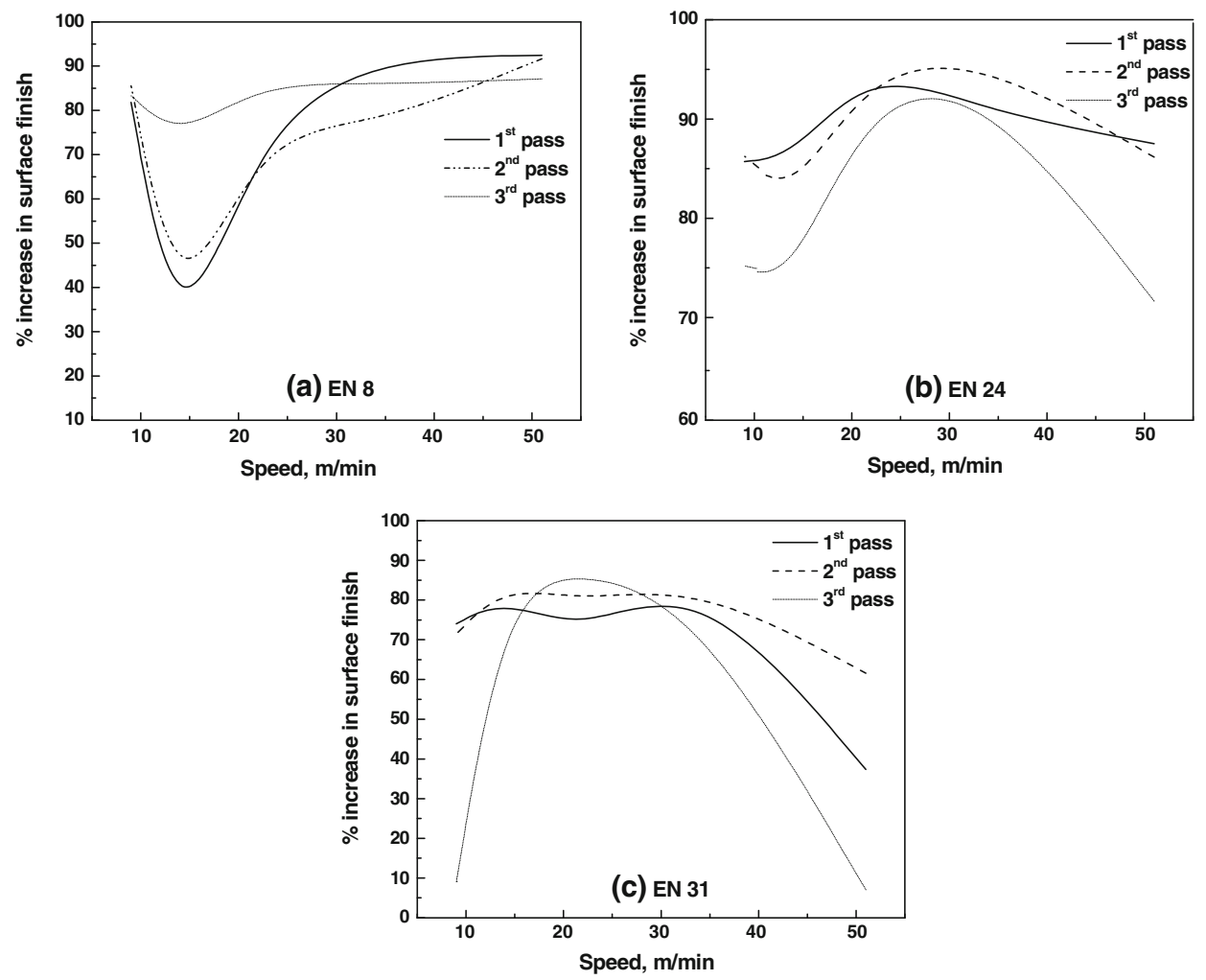

Figure 2. Variation of burnishing speed with \% increase in surface finish for different passes in (a) EN 8, (b) EN 24 and (c) EN 31 alloy steels. 

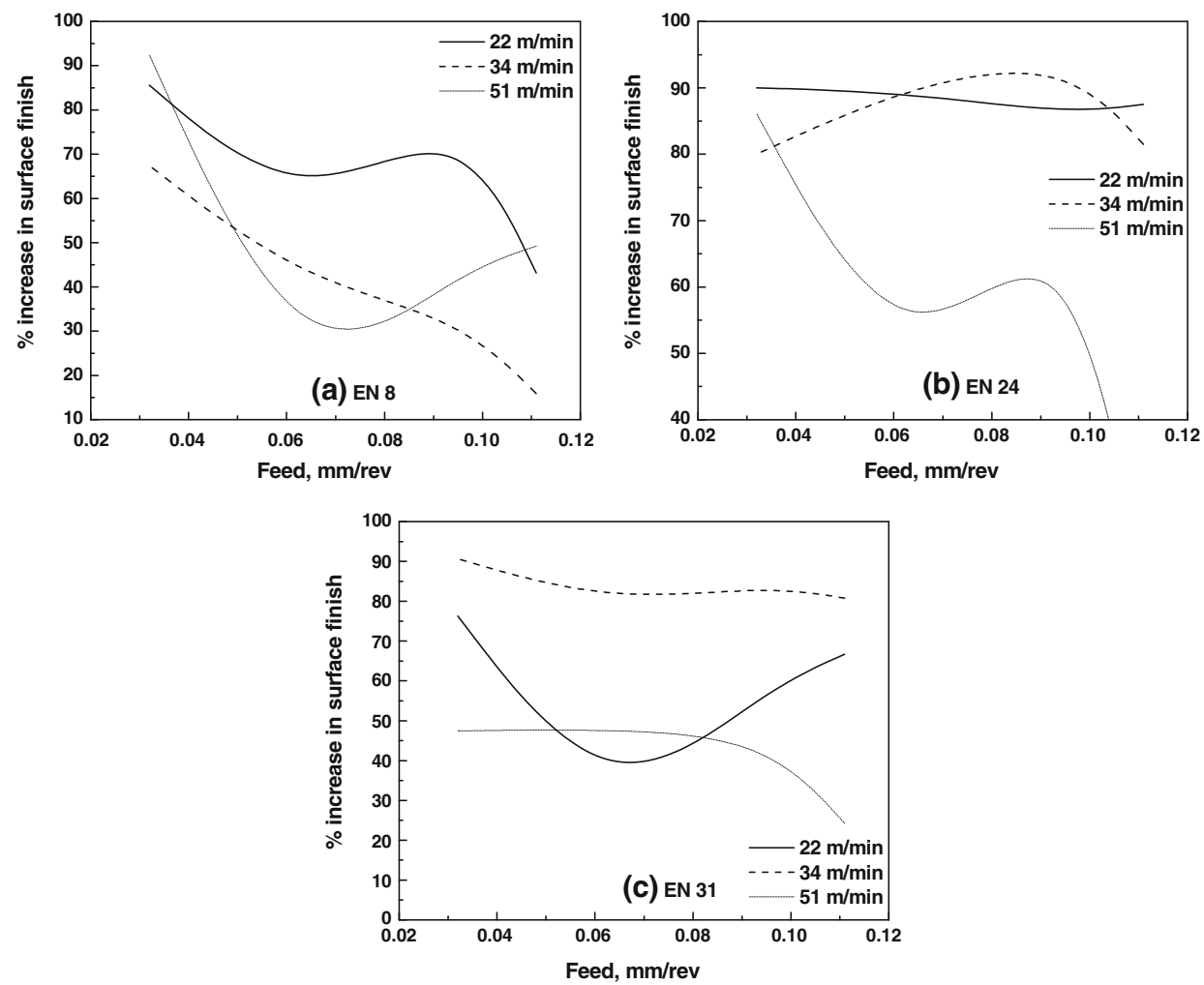

Figure 3. Variation of $\%$ increase in surface finish with burnishing feed for different feed in (a) EN 8, (b) EN 24 and (c) EN 31 alloy steels.

\subsection{Microstructure}

Figure 4 shows typical set of optical micrographs obtained from EN 8 alloy steel in the unburnished (figure $4 \mathrm{a}$ ) and burnished (figure $4 \mathrm{~b}$ for first pass, figure $4 \mathrm{c}$ for second pass, figure $4 \mathrm{~d}$ for third pass) conditions. The optical micrographs show similar structure with varied burnished depths for different burnishing conditions in all the other alloys - EN 24, EN 31, Al

Table 6. Variation of burnishing feed with $\%$ increase in surface finish at different speeds in (a) EN 8, (b) EN 24 and (c) EN 31 alloy steels, (d) aluminum alloy and (e) alpha-beta brass.

\begin{tabular}{lccccc}
\hline Material & $\begin{array}{c}\text { Speed } \\
(\mathrm{m} / \mathrm{min})\end{array}$ & $\begin{array}{c}\text { No. of } \\
\text { passes }\end{array}$ & $\begin{array}{c}\text { Force } \\
(\mathrm{N})\end{array}$ & $\begin{array}{c}\text { Feed } \\
(\mathrm{mm} / \mathrm{rev})\end{array}$ & $\begin{array}{c}\mathrm{R}_{\mathrm{a}} \\
(\mu \mathrm{m})\end{array}$ \\
\hline EN 8 & 51 & 1 & 210 & 0.032 & 0.10 \\
EN 24 & 34 & 2 & 170 & 0.095 & 0.15 \\
EN 31 & 34 & 1 & 200 & 0.032 & 0.11 \\
AA6061 & 14.57 & 3 & 110 & 0.032 & 0.12 \\
Alpha -beta brass & 22.6 & 1 & 140 & 0.063 & 0.19 \\
\hline
\end{tabular}




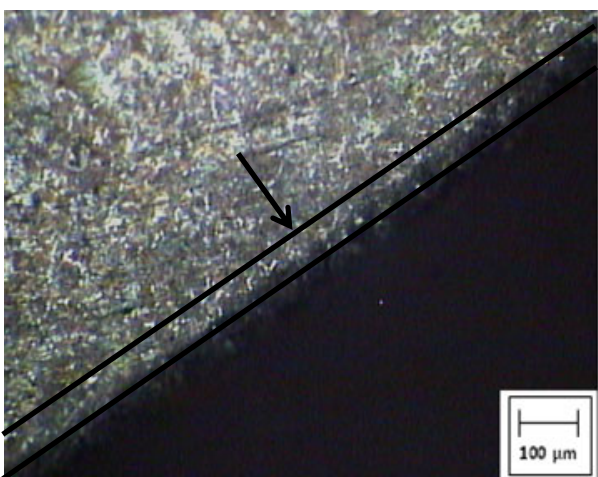

(a)

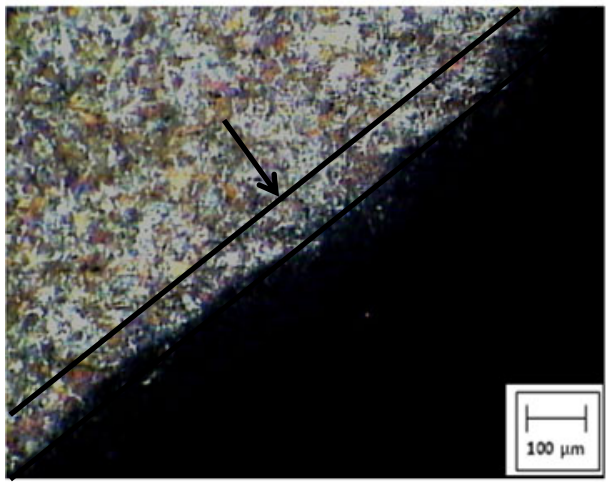

(c)

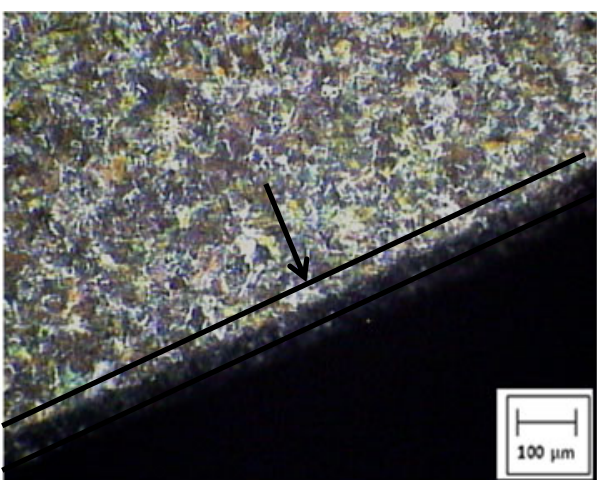

(b)

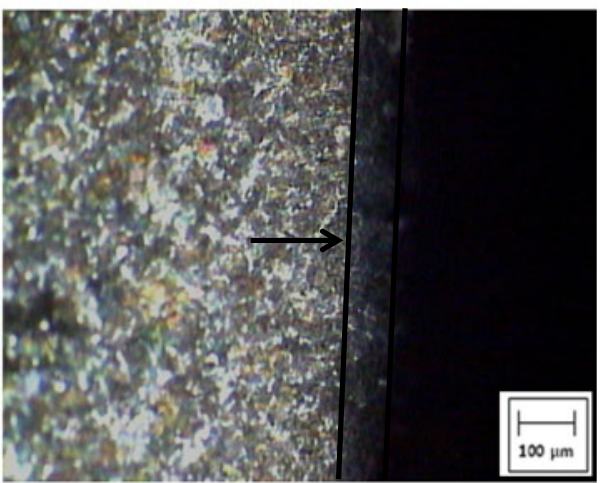

(d)

Figure 4. Optical micrograph of EN 8 showing the depth of burnishing in (a) unburnished, (b) burnished $-1^{\text {st }}$ pass, (c) burnished $-2^{\text {nd }}$ pass, (d) burnished $-3^{\text {rd }}$ pass condition.

Table 7. Variation of burnishing depth and average micro hardness values in the burnishing zone for three alloy steels, aluminum alloy and alpha-beta brass.

\begin{tabular}{|c|c|c|c|c|c|}
\hline \multirow[b]{2}{*}{ Material } & \multirow[b]{2}{*}{ Characteristic } & \multicolumn{4}{|c|}{ Burnishing process } \\
\hline & & $\mathrm{BB}$ & B1 & B2 & B3 \\
\hline \multirow[t]{2}{*}{$\overline{\mathrm{EN}} 8$} & Micro hardness & 251.2 & 303.5 & 279.4 & 294.3 \\
\hline & Burnishing layer & 260.0 & 475.0 & 425.0 & 350.0 \\
\hline \multirow[t]{2}{*}{ EN 24} & Micro hardness & 297.2 & 312.7 & 339.6 & 335.1 \\
\hline & Burnishing layer thickness & 250.0 & 350.0 & 450.0 & 430.0 \\
\hline \multirow[t]{2}{*}{ EN 31} & Micro hardness & 196.1 & 251.6 & 254.1 & 223.9 \\
\hline & Burnishing layer thickness & 400.0 & 650.0 & 700.0 & 675.0 \\
\hline \multirow[t]{2}{*}{ AA6061 } & Micro hardness & 89.4 & 106.8 & 111.8 & 98.3 \\
\hline & Burnishing layer thickness & 180 & 220 & 250 & 230 \\
\hline \multirow[t]{2}{*}{ Alpha -beta brass } & Micro hardness & 126.76 & 172.3 & 180.8 & 166.7 \\
\hline & Burnishing layer thickness & 410 & 650 & 700 & 450 \\
\hline
\end{tabular}

[BB - Before burnishing, B1 - Burnished- $1^{\text {st }}$ pass, B2 - Burnished- $2^{\text {nd }}$ pass and B3 - Burnished$3^{\text {rd }}$ pass] 
Table 8. Compressive residual stress for EN series steels, alumininium alloy and alphabeta brass from XRD analysis.

\begin{tabular}{lccccc}
\hline Burnishing & \multicolumn{5}{c}{ Compressive residual stress (MPa) } \\
\cline { 2 - 6 } condition & EN 8 & EN 24 & EN 31 & AA6061 & Alpha-beta brass \\
\hline BB & -170.65 & -208.1 & -159.83 & -6.66 & -8.82 \\
B1 & -223.46 & -272.07 & -208.10 & -22.28 & -68.64 \\
B2 & -202.93 & -293.30 & -175.10 & -69.88 & -51.33 \\
B3 & -204.76 & -248.72 & -170.65 & -39.31 & -42.13
\end{tabular}

$\left[\mathrm{BB}\right.$ - before burnishing, B1 - burnished- $1^{\text {st }}$ pass, B2 - burnished $-2^{\text {nd }}$ pass and B 3 - burnished$3^{\text {rd }}$ pass]
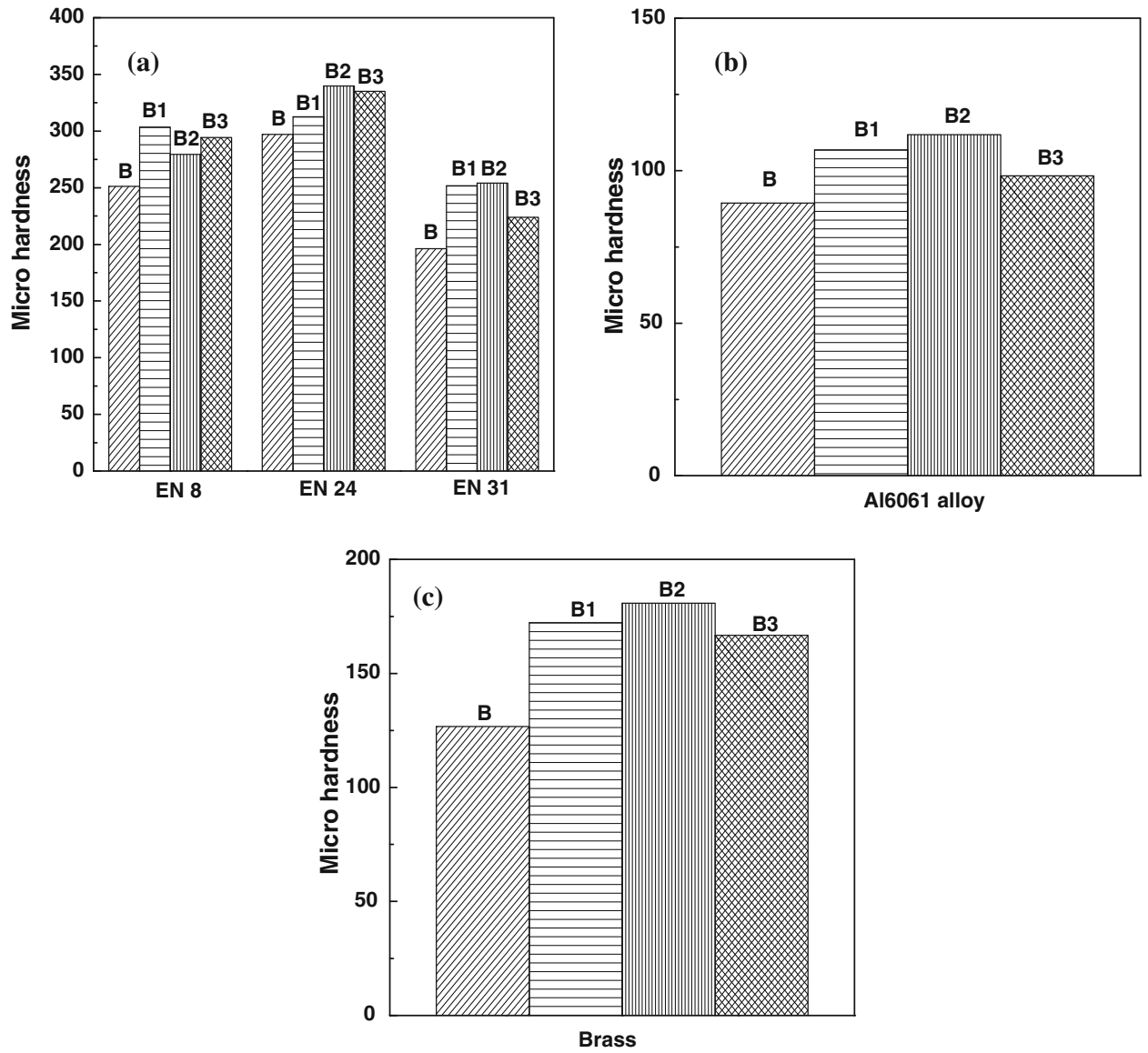

Figure 5. Correlation of surface micro-hardness with burnishing parameters (a) EN steels, (b) AA6061 alloy, (c) Alpha-beta brass (the designation B refers to unburnished condition; while B1, B2 and B3 refer to 1 st, 2nd and 3rd passes of burnishing, respectively). 
alloy AA6061 alpha-beta brass. These figures clearly show a distinct variation in the thickness of burnishing affected zone with each of the burnished pass. The variation in depth of these zones is measured from micrographs and the same are given in table 7 . These data clearly reveal that highest burnishing depth occurs at 1st pass in EN 8 and EN 31 while the same occurs at 2nd pass in EN 24 alloy steel. It should be noted here that the highest depth of burnishing presumably provides maximum effectiveness in surface modification. A summary of these experiments and evaluated data is included in table 7 (it should also be noted here that the pre-burnishing operations such as lathe turning too leaves behind surface modified layer, seen as small microstructure - modified surface layer in the unburnished material).

\subsection{Micro hardness}

The specimens polished to obtain microstructure were further used to determine the variation in micro hardness as a function of distance from the surface. The micro hardness values are found to be almost similar with no systematic variation with the burnishing distance from the surface. Hence, an average value of micro hardness is taken as a representative value for each of the experimental condition such as unburnished, burnished-1st pass, burnished2nd pass and burnished-3rd pass. These data are summarized and included in table 8 and are shown in figure 5. It is interesting to note that maximum burnished depth (as obtained from optical micrographs) also results in highest values of average micro hardness. The data obtained from other two materials $\mathrm{Al}$ alloy AA6061 and $\alpha-\beta$ brass are also included in figure 5 .

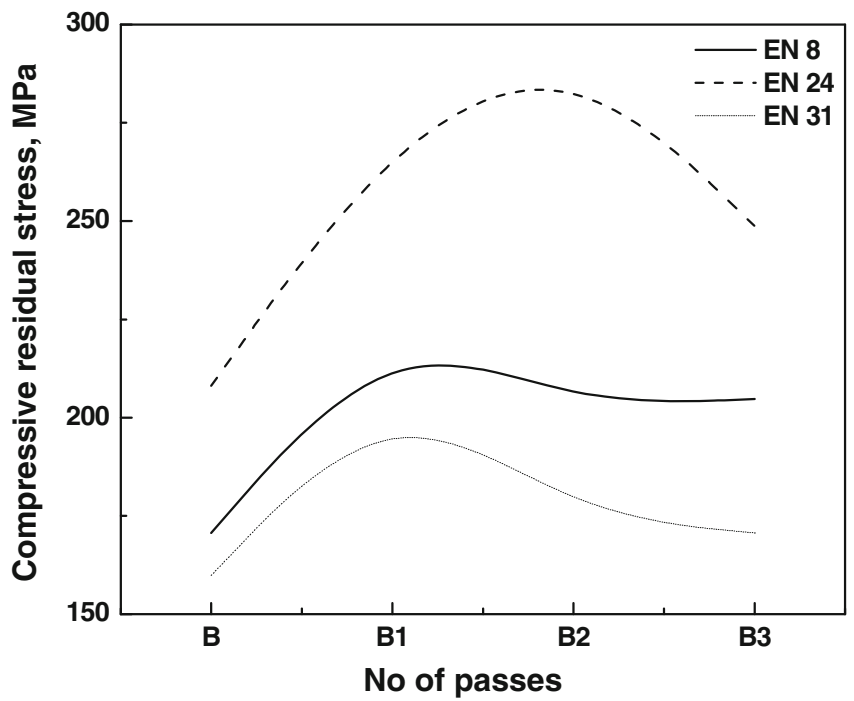

Figure 6. Variation of magnitude of residual compressive stresses with burnishing pass in case of the three alloy steels. 


\subsection{Residual stress}

The residual stresses, determined by XRD, are given in table 8 for all the five different metals and the same are shown in figure 6 (for the EN steels) as a function of number of passes for all the five materials. These data show that the residual stresses gradually build up with burnishing and exhibit a peak in residual stresses at 1st or 2nd burnishing pass. Unlike in EN 8 steel the
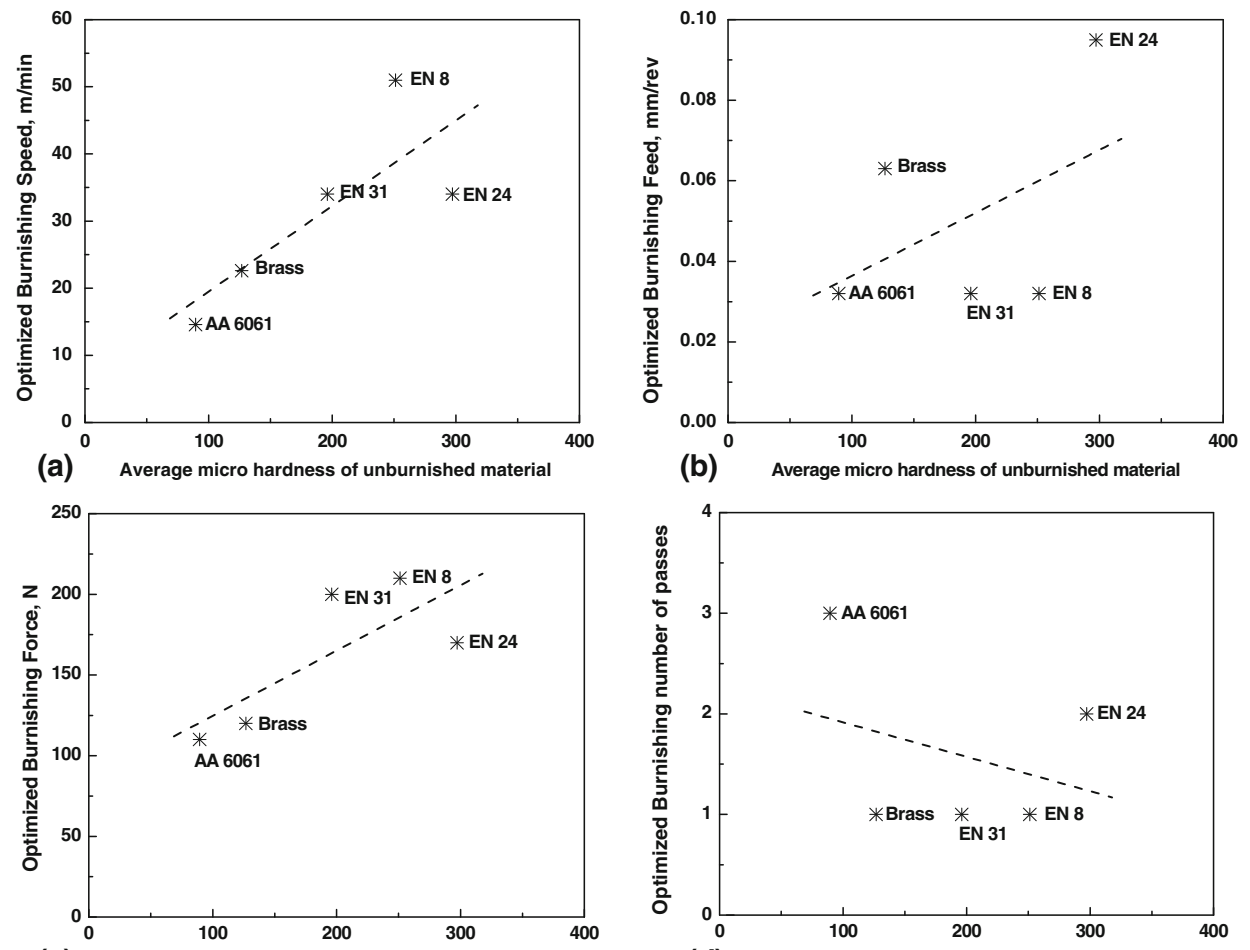

(c) Average micro hardness of unburnished material

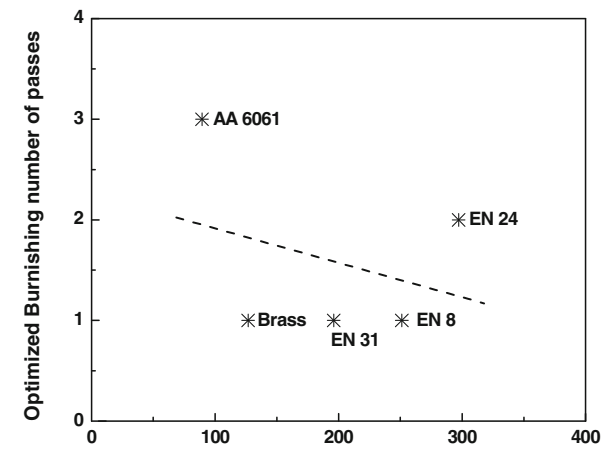

(d) Average micro hardness of unburnished material

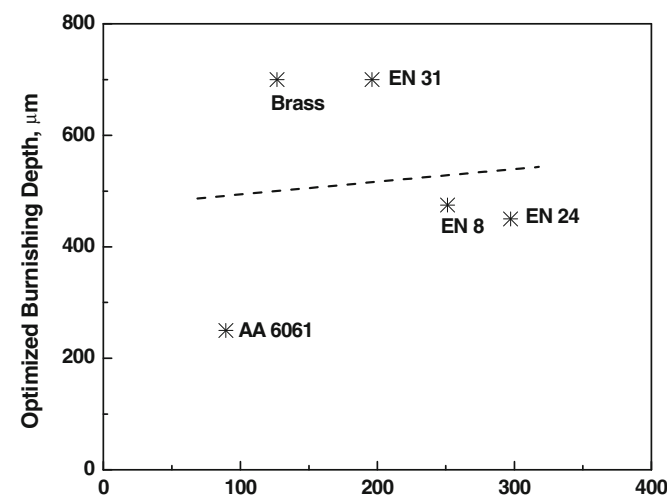

(e) Average micro hardness of unburnished material

Figure 7. Burnishing maps showing the variation in (a) burnishing speed, (b) burnishing feed, (c) burnishing force, (d) number of passes and (e) burnishing depth with average micro hardness of the unburnished material. 
other two alloy steels namely, EN 24 and EN 31 show significant decrease in the magnitude of compressive residual stresses. The data on other two materials, namely, Al Alloy AA6061 and alpha-beta brass are also included in table 8. The magnitude of compressive residual stress is also found to be strongly dependent on nature of engineering Al Alloy, especially its micro hardness. The harder is the alloy, the highest is the magnitude of compressive residual stresses. Burnishing depth too revealed a systematic correlation with the average hardness of the alloy steel. According to the expected lines, softest alloy of the three sets of materials exhibited the highest burnishing depth. The parameters chosen for XRD analysis are wave length: $2.291 \AA$, Bragg angle: $156^{\circ}$.

\subsection{Burnishing maps}

Based on the results obtained from the present experimental work, an attempt is made to construct burnishing maps by considering strength level of the material (in the present case average micro hardness of the unburnished experimental materials) as the base line and the varying burnishing parameters such as burnishing speed (figure 7a), burnishing feed (figure 7b) burnishing force (figure 7c), number of burnishing passes (figure 7d) and burnishing depth (figure 7e). The effect of burnishing force indirectly gets compensated in terms of varied time as well as depth of burnishing. Such correlation finally yield 'master burnishing map' by considering the variation of average micro hardness i.e., found to vary in the range between 89.4 (AA6061 alloy) and 297 (EN 24 alloy) and the corresponding optimized effective burnishing volume [(a product of $\pi \mathrm{d}$ (where d, diameter of work piece) and optimized results of burnishing speed, time of burnishing, no. of passes and depth of burnishing)] (figure 8). These maps clearly show that the optimal values of burnishing correspond to burnishing force, burnishing speed, burnishing feed and number of passes (data in tables 9 and 10).

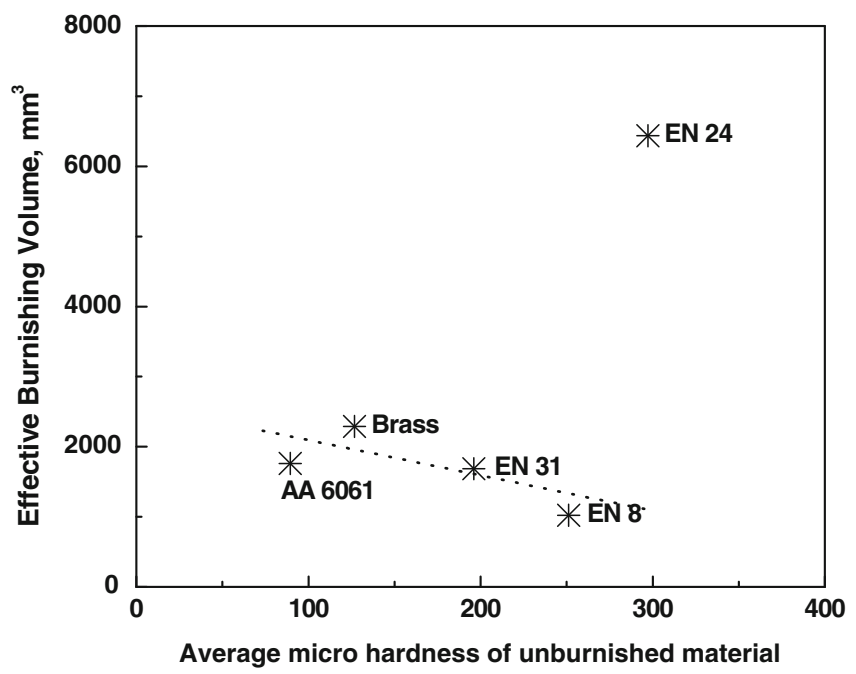

Figure 8. Master burnishing map showing a linearly decreasing burnishing volume with average micro hardness of unburnished material [note that the significantly high burnishing volume of EN 24 is due to the fact that optimized burnishing passes is 2 , instead of 1 as in the case of most other alloys]. 


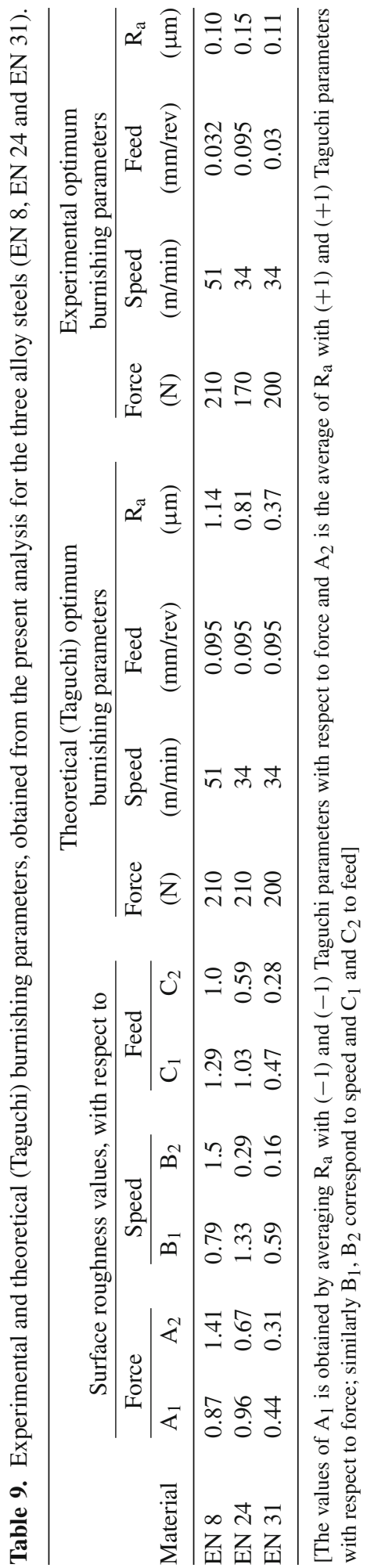


Table 10. Optimal parameters using Taguchi 3-level orthogonal method.

\begin{tabular}{|c|c|c|c|c|c|c|c|c|c|c|c|c|c|}
\hline \multirow[b]{3}{*}{ Material } & \multicolumn{9}{|c|}{ Surface roughness values, with respect to } & \multicolumn{4}{|c|}{$\begin{array}{l}\text { Theoretical (Taguchi) optimum } \\
\text { burnishing parameters }\end{array}$} \\
\hline & \multicolumn{3}{|c|}{ Force } & \multicolumn{3}{|c|}{ Speed } & \multicolumn{3}{|c|}{ Feed } & \multirow{2}{*}{$\begin{array}{l}\text { Force } \\
(\mathrm{N})\end{array}$} & \multirow{2}{*}{$\begin{array}{l}\text { Speed } \\
(\mathrm{RPM})\end{array}$} & \multirow{2}{*}{$\begin{array}{c}\text { Feed } \\
(\mathrm{mm} / \mathrm{rev})\end{array}$} & \multirow{2}{*}{$\begin{array}{c}\mathrm{R}_{\mathrm{a}} \\
(\mu \mathrm{m})\end{array}$} \\
\hline & $\mathrm{A}_{1}$ & $\mathrm{~A}_{2}$ & $\mathrm{~A}_{3}$ & $\mathrm{~B}_{1}$ & $\mathrm{~B}_{2}$ & $\mathrm{~B}_{3}$ & $\mathrm{C}_{1}$ & $\mathrm{C}_{2}$ & $\overline{\mathrm{C}_{3}}$ & & & & \\
\hline EN 8 & 0.66 & 0.95 & 0.46 & 0.80 & 0.25 & 0.89 & 0.83 & 0.61 & 0.60 & 200 & 534 & 0.063 & 0.22 \\
\hline EN 24 & 1.19 & 0.31 & 0.36 & 0.77 & 0.33 & 0.77 & 0.62 & 0.49 & 0.75 & 200 & 355 & 0.095 & 0.11 \\
\hline EN 31 & 0.51 & 0.14 & 0.38 & 0.40 & 0.32 & 0.40 & 0.39 & 0.28 & 0.46 & 200 & 355 & 0.095 & 0.06 \\
\hline
\end{tabular}

[The values of $A_{1}, A_{2}$ and $A_{3}$ are obtained by averaging the surface roughness values with respect to (w.r.t.) force. $B_{1}$, $B_{2}$ and $B_{3}$ are obtained by averaging the surface roughness values with respect to (w.r.t.) speed. Similarly, $C_{1}, C_{2}$ and $\mathrm{C}_{3}$ are obtained by averaging the surface roughness values with respect to feed]

\section{Technological implication}

Surface compressive residual stresses have been found to be beneficial for tensile mean stress controlled fatigue as well as creep. The same would be grossly detrimental to the conditions where compressive mean stress is in effect (Suresh 1983; Malakondaiah \& Nicholas 1994; Eswara Prasad et al 2000). However, in most engineering applications, the rotary parts grossly experience tensile loading conditions and compressive residual stresses are thus desirable and they effectively enhance fatigue resistance. Hence, burnishing is highly beneficial for most rotating structural components in improving their service life. Further studies are required to evaluate the effectiveness of compressive residual stresses that result an industrial burnishing process by extending the present studies to at least high cycle fatigue loading. Such studies also need to address the progressive relaxation in the net compressive residual stresses with the extent of high cycle fatigue damage as occurs with number of such fatigue cycles. These studies have not been attempted till date and should be of significant technological value in case of present low-cost EN series alloy steels.

\section{Conclusions}

(i) Burnishing results in significant surface finish, depth of burnishing and increase in micro hardness and residual stresses. The present systematic study reveals that the burnishing depth, increase in micro hardness or increase in magnitude of compressive residual stresses, is higher in case of softer alloy steel EN 31 as compared to the relatively harder EN 8 and EN 24 alloy steels. In all the three alloy steels, higher extent of burnishing resulted in different extents of micro structural modification (as reflected by the magnitude of compressive residual stresses) and in general, showed a maximum at intermediate burnishing pass - first in case of EN 8, EN 31 and second in case of EN 24 steel of the three passes studied in this investigation. Surface roughness is most influenced by burnishing force in case of EN 8; by burnishing speed in case of EN 24 and EN 31.

(ii) The optimum speed, force and feed for minimum roughness are $535 \mathrm{rpm}, 200 \mathrm{~N}$, $0.063 \mathrm{~mm} / \mathrm{rev}$ for EN 8 and $355 \mathrm{rpm}, 200 \mathrm{~N}, 0.095 \mathrm{~mm} / \mathrm{rev}$ for EN 24 and EN 31 alloy steels, which is nearly matched with the values obtained by theoretical Taguchi method (see data in tables 9 and 10). Also note that the data in table 10 (level -3 analysis) is only a refinement and level 2 analysis (table 9) and does not alter the nature of influence. 
(iii) With the present data where the numbers of passes are restricted to 3, the aluminum alloy AA6061 shows best surface finish in the second pass (though the third pass does not show much degradation in surface finish). Maximum burnishing depth happens to occur in 2nd pass. However, it should be noted that the variation in burnishing depth with extent of burnishing is less pronounced in the present alloy as compared to EN series steels.

(iv) Mechanically modified layer of varied thickness was found to be present at the surface as a consequence of burnishing values of burnishing depth as a function of extent of burnishing (unburnished, 1st, 2nd and 3rd passes). The present study shows that for $\alpha-\beta$ brass, the maximum burnishing depth happens to occur in 1st pass.

(v) The present study revealed one-to-one correlations between burnishing depth, increase in micro hardness and magnitude of compressive residual stresses.

(vi) Attempts are made in the present investigation to construct 'burnishing maps' correlating various burnishing parameters with average micro hardness of unburnished material. These 'burnishing maps' show a good linear correlation with burnishing speed, burnishing force and burnishing depth, while the same for burnishing feed and number of burnishing passes is less deterministic (figure 7). On the other hand, the 'master burnishing map' (figure 8) considering the effective burnishing volume and its correlation with average micro hardness of unburnished material is found to be linear except in the case of EN 24 steel, where it is of higher hardness and having optimal burnishing passes as 2 instead of 1 in case of most of the materials.

\section{Acknowledgements}

The authors express their sense of gratitude to Mr K Srikanth of Defence Research and Development Laboratory, Hyderabad, for his help in the measurements of residual stresses and Ms $\mathrm{S}$ Srilatha of RCMA (Mat), CEMILAC, Hyderabad for her help in microstructural evaluation and microhardness measurements. One of the authors NEP would like to thank Dr K Tamilmani, Distinguished Scientist and Chief Executive (Airworthiness) CEMILAC, Bangalore for his support and encouragement.

\section{References}

Belov V A 1966 Technical and Economic aspects of ball burnishing. Russian Eng. J. XLVI: 79-81

Brinksmeier E 1982 Residual stresses measurement and causes in machining process. Annals of the CIRP 31: 491-510

Chepa P A and Andrayshin V A 1973 Residual stresses in components work hardened by burnishing. Russian Eng. J. 53: 34-35

Eswara Prasad Namburi, Dagmar Vogt, Thomas Bidlingmaier, Alexander Wanner and Eduard Arzt 2000 Effect of prior fatigue exposure on the creep behavior of an Aluminium alloy (Al-12Si-CuMgNi). $Z$. Metallkd 91: 190-195

Jack R Clark and Marion B Grant 1992 The effect of surface finish on component performance. Int. J. Mech. Tools Manufact. 32: 57-66

Kotiveerachari B and Murthy RL 1988 Estimation of depth of plastic deformation layer in burnishing. Proceeding of 13th ATMIDR, Calcutta D24-D30

Kotiveerachari B and Murthy RL 1989 Study of some aspects of burnishing. Int. J. Production Res. 23: 499-521

Malakondaiah G and Nicholas T 1994 The influence of laser glazing on fatigue crack growth in Ti-24Al11Nb. Metallurgical and Materials Transactions A 25: 183-192

Papshev D D 1966 Increasing the life of hardened steel parts by burnishing. Russian Eng. J. XLVI: 60-64 
Phadke S M 1989 Quality engineering using robust design. Englewood Cliffs, NJ: Prentice Hall Phillip J Ross 2008 Taguchi techniques for quality engineering. Noida, India: TATA Mc-GRAW Hill

Rajesham S and Jem Cheong Tak 1989 A study on the surface characteristics of burnished components. J. Mech. Working Technol. 20: 129-138

Ruseva E V and Fuks M Ya 1978 Surface layer properties after burnishing by different methods. Russian Eng. J. 58: 28-30

Shapiro A A and Frolov S F 1970 Influence of surface work hardening on the fatigue properties of wrought iron. Russian Eng. J. L: 52-53

Sheider Yu G 1967 Characteristics of burnished components. Machines and Tooling 33: 19-22

Sheider Yu G 1970 Contact area of vibro-burnished surfaces. Russian Eng. J. L: 34-39

Suresh S 1983 Micromechanisms of fatigue crack growth retardation following overloads. Eng. Fracture Mech. 18: 577-593

Timoshchenko V A and Dubenko V V 1976 Selection of optimum technological parameters for diamond burnishing of chromium coated blanks. Russian Eng. J. 56: 57-58

Torbilo V M and Markus L I 1969 Residual stresses in hardened steel surfaces after diamond burnishing. Russian Eng. J. XLIX: 46-47

Vyallo A A 1965 Combined turning and burnishing operations. Machines and Tooling 36: 27-29 